ISSN 1112-9867

Available online at

http://www.jfas.info

\title{
A CONVENIENT SYNTHESIS OF PYRANDIONE DERIVATIVES USING
}

P-TOLUENESULFONIC ACID AS CATALYST UNDER ULTRASOUND

IRRADIATION

\author{
N. Benosmane ${ }^{1,2, *}$, B. Boutemeur ${ }^{2}$, S.M. Hamdi ${ }^{3}$, M. Hamdi ${ }^{2}$ \\ ${ }^{1}$ Département de Chimie, Faculté des Sciences, Université M'Hamed Bougara de Boumerdès \\ (UMBB), Avenue de l'indépendance-35000-Algérie. \\ ${ }^{2}$ Laboratoire de Chimie Organique Appliquée. Faculté de Chimie, USTHB BP 32 El-Alia \\ 16111, Alger, Algérie. \\ ${ }^{3}$ Clinical Biochemistry Department, CHU Toulouse, University of Toulouse, UPS, Toulouse, \\ France
}

Received: 28 April 2016 / Accepted: 25 August 2016 / Published online: 01 September 2016

\begin{abstract}
A new series of 3,3'-\{alkane- $\alpha, \omega$-diylbis[imino-eth-1-yl-1-ylidene] $\}$ bis(6-methyl-2H-pyran2,4(3H)-dione) derivatives (3c-e) has been synthesized by the convenient ultrasound-mediated condensation of a diamine with dehydroacetic acid in the presence of a catalytic amount of p- toluenesulfonic acid. The structure of all synthesized compounds was elucidated by IR spectroscopy, ${ }^{1} \mathrm{H}$ NMR spectroscopic spectra, elemental analysis, and mass spectroscopy. A tautomeric form for the derivatives species is also proposed.
\end{abstract}

Keywords: Dehydroacetic acid; Schiff base; Condensation; Catalyst; Ultrasound irradiation; Tautomerism.

Author Correspondence, e-mail: nadjibbenosmane@yahoo.fr doi: http://dx.doi.org/10.4314/jfas.v8i3.9

\section{INTRODUCTION}

3-acetyl-4-hydroxy-6-methyl-2-pyrone 1 (dehydroacetic acid: DHA) and its derivatives 
now constitute an important group of organic products, which are used as food additives [1], anticoagulants and cosmetic products [2]. It was first prepared by Geuther (1866) from the acetoacetic ester. Both dehydroacetic acid and its sodium salt are used as fungicides and have been applied as food preservatives [3]. The DHA condensation reaction with bis nucleophiles allows interesting heterocyclic compounds derived from pyridopyrimidine, the thiazolopyrimidine and pyridine [4]. The incorporation of a heterocyclic moiety in pyrones either in the form of a substituent can alter the biological activity.

Studies on the metal chelates with Schiff base of dehydroacetic acid have been reported due to their excellent chelating capacity in modern coordination chemistry [5-8]. For decades, coordination chemistry of Schiff base ligands has been studied. The synthesis of novel Schiff bases and the research of their physiological activities have become important due to their anticancer and antimicrobial activities $[9,10]$. This molecule is very promising because it presents a complicated set of tautomeric equilibria (see Scheme 2) and consequently high reactivity (as well as most enamines) towards metal ions.

Our literature investigation confirms that there are no reports on the synthesis of pyran dione under ultrasound irradiation catalyzed by p-TSA. In this stage, our main approach is to improvement a green organic reaction methodology, which is moderately faster and cleaner than conventional reaction. In this paper, we report a novel and efficient method for the synthesis of a new 3,3'-\{alkane- $\alpha, \omega$-diylbis[imino-eth-1-yl-1-ylidene]\}bis(6-methyl2H-pyran-2,4(3H)-dione) derivatives: 3(c-e) via an efficient condensation of diamine $\mathbf{1}$ and dehydroacetic acid $\mathbf{2}$ in ethanol in the presence of p-toluenesulfonic acid (p-TSA) as catalyst under ultrasonic irradiation (Scheme 1), 


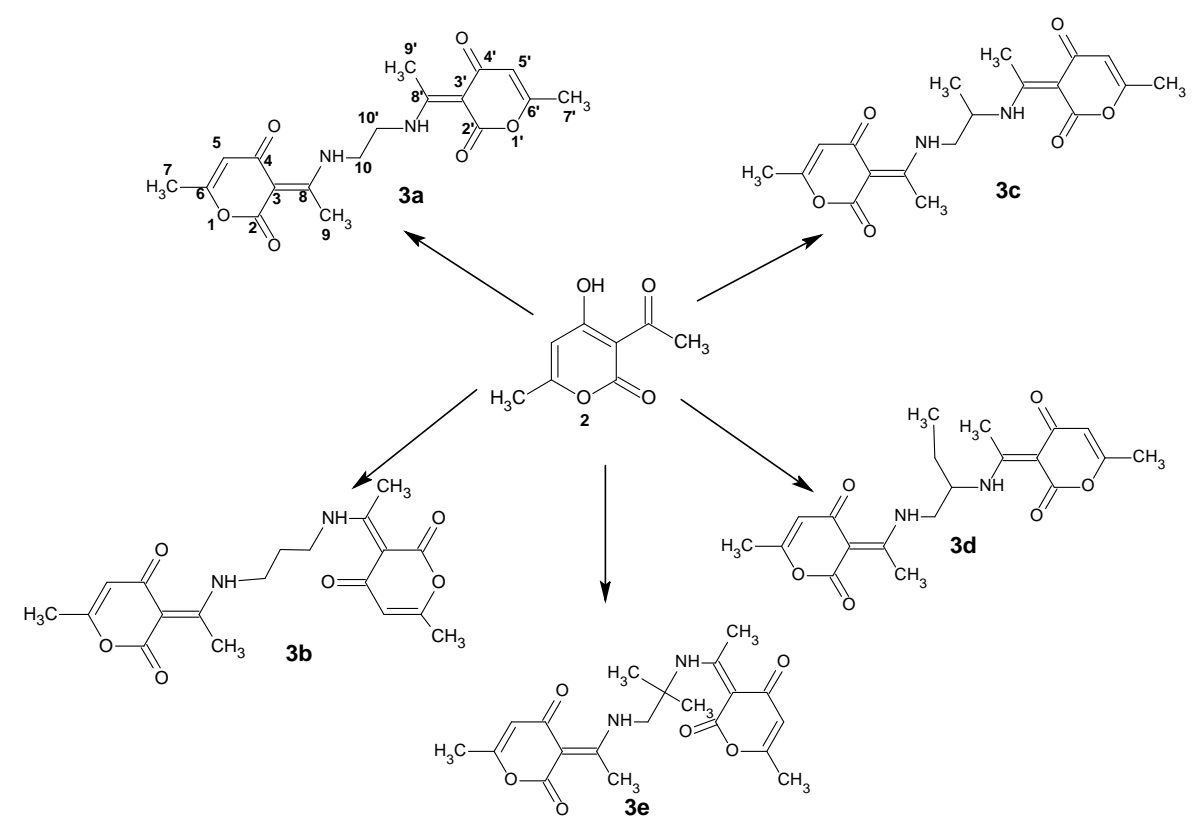

Scheme 1

\section{RESULTS AND DISCUSSION}

The preliminary tests of the synthesis of Schiff base derived from primary-diamine with conventional method indicate that this is not likely to be a useful process (Table 1), probably due to the low basicity and low solubility of diamine make their condensation with dehydroacetic acid relatively difficult. Ultrasounds can promote for realizing many reactions [11-13], most of the effects arise from cavitations [14-15]. In the literature, it is shown that increase in yield is observed upon condensation reaction using ultrasounds. A large number of reactions can be carried out in higher yield [6, 16-22]. Consequently, we chose to examine the effect thereof on the synthesis of Schiff bases.

In the context of this communication, the development of practical and efficient methodologies for the synthesis of $3, \quad \mathbf{3}^{\prime}$-\{alkane- $\boldsymbol{\alpha}, \boldsymbol{\omega}$-diyl bis [imino-eth-1-yl-1-ylidene] \}bis(6-methyl-2H-pyran-2,4(3H)-dione) derivatives 3 is still gaining interest. 
Table 1. Synthesis of $3,3^{\prime}-\{$ alkane- $\alpha, \omega$-diylbis[imino-eth-1-yl-1-ylidene] $\} b i s(6-m e t h y l-$ $2 H$-pyran-2,4(3H)-dione) derivatives (3a-e) under conventional method with p-TSA as catalyst

\begin{tabular}{|c|c|c|c|c|c|}
\hline \multicolumn{2}{|l|}{ Alkane-Diamine } & \multirow{3}{*}{$\begin{array}{l}\text { Product } \\
\text { 3a }\end{array}$} & \multirow{3}{*}{$\begin{array}{ll}\mathbf{m . p}\left({ }^{\circ} \mathbf{C}\right) & \\
& \\
260-262 \quad(265) \\
{[22]}\end{array}$} & \multicolumn{2}{|c|}{ Conventional method } \\
\hline & & & & Time (h) & Yield (\%) \\
\hline Ethane-1,2-diamine & $1 \mathrm{a}$ & & & 3 & 60 \\
\hline $\begin{array}{l}\text { Propane-1,3-diamin } \\
\text { e }\end{array}$ & $\mathbf{1 b}$ & $3 b$ & $\begin{array}{l}217-219 \\
(214-215)[5]\end{array}$ & 3 & 63 \\
\hline $\begin{array}{l}\text { Propane-1,2-diamin } \\
\text { e }\end{array}$ & $1 \mathrm{c}$ & $3 c$ & $223-225$ & 3 & 65 \\
\hline Butane-1,2-diamine & 1d & $\mathbf{3 d}$ & $120-121$ & 3 & 56 \\
\hline $\begin{array}{l}\text { 2-Methyl propane } \\
\text {-1,2-diamine }\end{array}$ & $1 e$ & $3 \mathbf{e}$ & 204-206 & 8,5 & 35 \\
\hline
\end{tabular}

To obtain suitable conditions for the synthesis of 3, 3'-\{alkane- $\alpha$, $\omega$-diylbis[imino-eth-1-yl-1-ylidene]\}bis(6-methyl-2H-pyran-2,4(3H)-dione) derivatives 3 , various reactions conditions have been investigated in the reaction of 1,3-diamino propane $\mathbf{1 b}$, and dehydroacetic acid (DHA) 2 as a model reaction.

First, we verified the effect of the solvent, the ultrasonic assisted reaction of the aliphatic diamines and dehydroacetic acid in presence catalytic amount of p-TSA was examined using, acetonitrile, chloroform, methanol and ethanol as solvent, the results were listed in Table 2. Chloroform and acetonitrile give moderate yields of the desired product $3 \mathrm{a}$, 
Table 2. The model reaction catalyzed by p-TSA in different solvents under ultrasound irradiation

\begin{tabular}{|l|l|l|l|}
\hline Solvent & $\mathbf{T}\left({ }^{\circ} \mathbf{C}\right)$ & Time (h) & Yield ${ }^{\mathbf{b}}(\%)$ \\
\hline Ethanol & 30 & 1 & 83 \\
\hline Methanol & 30 & 2,5 & 74 \\
\hline chloroform & 30 & 3 & 60 \\
\hline Acetonitrile & 30 & 7 & 40 \\
\hline
\end{tabular}

${ }^{\text {a }}$ Reaction conditions : diamine $(10 \mathrm{mmol})$, dehydroacetic acid $(20 \mathrm{mmol})$ and p-TSA (10mmol), solvent ( 10ml) and ultrasonic power $180 \mathrm{~W}$, irradiation frequency $40 \mathrm{kHz}$.

${ }^{\mathrm{b}}$ yields of isolated product $\mathbf{3 b}$.

In addition, the time of reaction is long and the yields were low. However, the reaction using ethanol as solvent afforded the right result (Table 2). Thus, ethanol was selected as a solvent for all further reactions. In order to apply this reaction, we have applied the reaction of aliphatic diamines with dehydroacetic acid under similar conditions (ethanol $/ 30^{\circ} \mathrm{C} / \mathrm{ultrasound} / \mathrm{p}-\mathrm{TSA}$ ) furnishing the respective $3,3^{\prime}-\{$ alkane- $\alpha, \omega$-diylbis[iminoeth-1-yl-1-ylidene] \}bis(6-methyl-2H-pyran-2,4(3H)-dione) derivatives in good yields (Scheme 1). The optimized results are summarized in Table 3. we found that the results were best in terms of yields for 3(a-d) under same conditions, however, the reaction with diamine 1e required a longer time and the yield of product (3e) notably decreased (Table 3), probably due to the large steric effect of substituent in diamine. That is to say, steric factors played a key role in affecting the rates of reaction and the reaction required a larger time [6]. 
Table 3. Synthesis of 3,3'-\{alkane- $\alpha, \omega$-diylbis[imino-eth-1-yl-1-ylidene] $\}$ bis(6-methyl- $2 H$ pyran-2,4(3H)-dione) derivatives (3a-e) under ultrasonic irradiation with p-TSA as catalyst

\begin{tabular}{|c|c|c|c|c|c|}
\hline \multicolumn{2}{|l|}{ Alkane-Diamine } & \multirow{3}{*}{$\begin{array}{l}\text { Product } \\
3 a\end{array}$} & \multirow{3}{*}{$\begin{array}{l}\text { m.p }\left({ }^{\circ} \mathbf{C}\right) \\
\\
260-262 \quad(265) \\
{[22]}\end{array}$} & \multicolumn{2}{|c|}{ Sonochemical method } \\
\hline & & & & Time (h) & Yield (\%) \\
\hline Ethane-1,2-diamine & $1 \mathbf{a}$ & & & 1 & 80 \\
\hline $\begin{array}{l}\text { Propane-1,3-diamin } \\
\text { e }\end{array}$ & $1 \mathbf{b}$ & $3 \mathbf{b}$ & $\begin{array}{l}217-219 \\
(214-215)[5]\end{array}$ & 1 & 83 \\
\hline $\begin{array}{l}\text { Propane-1,2-diamin } \\
\text { e }\end{array}$ & 1c & $3 c$ & $223-225$ & 1 & 80 \\
\hline Butane-1,2-diamine & 1d & 3d & $120-121$ & 1,5 & 85 \\
\hline $\begin{array}{l}\text { 2-Methyl propane } \\
\text {-1,2-diamine }\end{array}$ & $\mathbf{1 e}$ & $3 \mathbf{e}$ & 204-206 & 4 & 50 \\
\hline
\end{tabular}

Hence, the reactions times increased considerably and the yields of the products decreased under conventional reflux conditions. Thus, ultrasonic irradiation was found to have a favorable offect the synthesis of 3,3'- $\{$ alkane- $\alpha, \omega$-diylbis[imino-eth-1-yl-1-ylidene] $\}$ bis(6-methyl-2 $H$-pyran-2,4(3H)-dione) derivatives which was important compared to the traditional method with respect to yield, reactions times, simplicity and safety.

The structure and purities of the obtained products (3a-e) were deduced from their elemental analysis, IR spectrum, ${ }^{1} \mathrm{H}-\mathrm{NMR}$ analyses, and mass spectrometry data. As a representative example, a comparison of the IR spectra of the dehydroacetic acid (DHA) and Schiff base gives us the proof about the formation of the Schiff base. The main bands in the IR spectrum of the DHA absorption band at $1659 \mathrm{~cm}^{-1}$ of the acetyl $\mathrm{C}=\mathrm{O}$ was disappeared in the Schiff 
base, which indicate that the condensation has occurred with the amino groups of diamine. The IR spectral data of the Schiff base showed characteristic absorption bands at 3451, 1705, 1666, and 1568 which may be assigned to intramolecular hydrogen bonded in $v(\mathrm{NH})$ (scheme 2), lactone carbonyl $v(\mathrm{C}=\mathrm{O})$, and those at 1666 and 1568 to extra cyclic $v(\mathrm{C}=\mathrm{C})$ [22]. Schiff base it can be formulated with Keto-Amine structure 3a (II) reported in Scheme 2.

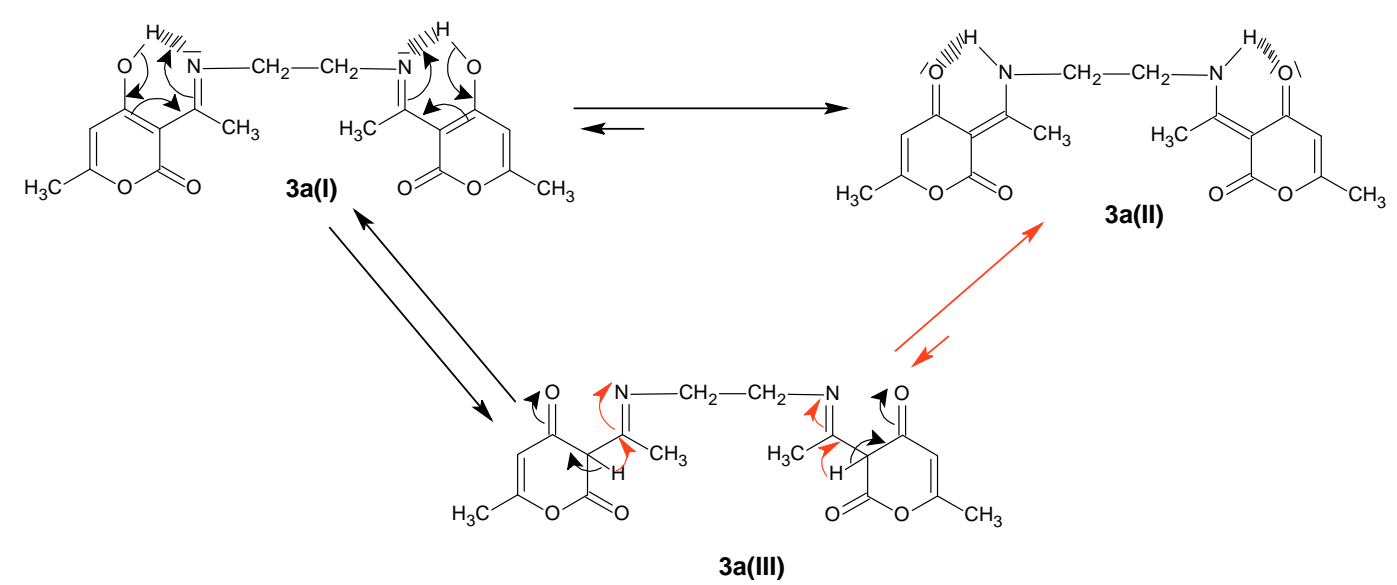

Scheme 2. Proposed tautomeric form of Schiff base 3a

The ${ }^{1} \mathrm{H}$ NMR spectrum of 3a showed characteristic singlet signal at 2,07 ppm assigned to proton resonances of the methyl group in position 7 and 7', singlet signal at 2,57 ppm which might attributed to $\left(2 \mathrm{CH}_{3}\right)$ in position 9 and 9', multiplet signal at 3,83-3,90 ppm attributed to $\left(2 \mathrm{CH}_{2}\right)$, singlet signal at $5,7 \mathrm{ppm}$ to proton in the $(=\mathrm{C}-\mathrm{H})$ in position 5 and 5 , in addition to a broad exchangeable signal at $13,8 \mathrm{ppm}$ characteristic of $-\mathrm{NH}^{5}$. Its ${ }^{1} \mathrm{H}$ NMR spectrum in $\mathrm{CDCl}_{3}$ is very similar to those of other 'Schiff base' derivatives of dehydroacetic acid, which are known to prefer the Keto-amine tautomeric form 3a (II) rather than the enol-iminone [5]. The data described for $\mathbf{3 a}$ are analogue to the other derivatives that allowed us to conclude that we have only obtained 3,3'-\{alkane- $\alpha, \omega$-diylbis[imino-eth-1-yl-1-ylidene] $\}$ bis(6-methyl2H-pyran-2,4(3H)-dione) derivatives 3(a-e). 


\section{EXPERIMENTAL}

\subsection{General}

All reagents were purchased from commercial sources and used without further purification. Ultrasonication was performed in an ultrasound BRANSON 5510 with the frequency of 40 $\mathrm{kHz}$ and an output power $185 \mathrm{~W}$, the reaction temperature was controlled by addition or removal of water from the ultrasonic bath. Melting points were established on a Stuart scientific SPM3 apparatus fitted with a microscope and are uncorrected. The IR spectra were recorded on FT-IR (Shimadzu) instrument model 4000 in anhydrous $\mathrm{KBr}$ pellets in the range of $4000-400 \mathrm{~cm}^{-1}$. ${ }^{1} \mathrm{H}$ NMR spectra were recorded in $\mathrm{CDCl}_{3}$ solutions on Bruker Avance 300

(300.13 MHz for $\left.{ }^{1} \mathrm{H}\right)$ spectrometer. Chemical shifts are reported in parts per million $(\delta, \mathrm{ppm})$ using TMS as an internal reference. Mass spectra are obtained with EI. Positive-ion ESI mass spectra were acquired using a TOF-MS 2 instrument.

\subsection{Traditional procedure for the synthesis of 3,3'-\{alkane- $\alpha, \omega$-diylbis[imino-eth-1-yl-1-} ylidene]\}bis(6-methyl-2H-pyran-2,4(3H)-dione) derivatives (3a-e)

A $100 \mathrm{ml}$ flask was loaded with diamine 1 (10 mmol), dehydroacetic acid 2 (20 mmol) in ethanol $(30 \mathrm{ml})$. The mixture was stirred and refluxed for the appropriate amount of time, after the completion of the reaction verifying by thin layer chromatography (TLC), using a 6:1 mixture of Chloroform/Methanol, the reaction was allowed to cool, and the ethanol was evaporated under reduced pressure. The crude compounds thus obtained were recrystallized from ethanol to give pure compounds $\mathbf{3 a}-\mathbf{e}$.

\subsection{Ultrasound-promoted synthesis of 3,3 '-\{alkane- $\alpha, \omega$-diylbis[imino-eth-1-yl-1-} ylidene]\}bis(6-methyl-2H-pyran-2,4(3H)-dione) derivatives (3a-e)

A $100 \mathrm{ml}$ flask was charged with diamine $1(10 \mathrm{mmol})$, dehydroacetic acid $2(20 \mathrm{mmol})$ and p-TSA $(10 \mathrm{mmol})$ in ethanol $(10 \mathrm{ml})$. The mixture was sonicated in the water bath of an ultrasonic cleaner at $30{ }^{\circ} \mathrm{C}$. After the completion of the reaction as indicated by thin layer chromatography (TLC), using a 6:1 mixture of Chloroform/Methanol, the reaction was allowed to cool, and the ethanol was evaporated under reduced pressure. The crude compounds thus obtained were recrystallized from ethanol to give pure compounds $\mathbf{3 a}-\mathbf{e}$. 
4.3.1.

3,3'-\{ ethane-1,2-diylbis[imino-eth-1-yl-1-ylidene] \}bis(6-methyl-2H-pyran-2,4(3H)-dione)

(3a). Pale yellow solid, m.p: 260-262 ${ }^{\circ} \mathrm{C}$ (265) [22] (recrystallized from ethanol, TLC-chloroform: methanol, 6:1, $\left.\mathrm{R}_{\mathrm{f}}=0.67\right) ; 2,88 \mathrm{~g}(80 \%) . \quad \mathrm{IR}\left(\mathrm{KBr}, \mathrm{cm}^{-1}\right): 3451,3053$, 1708, 1661, 1571, 1469, 1390, 943, 823, 777. ${ }^{1} \mathrm{H}$ NMR $\left(\mathrm{CDCl}_{3}, 300,13 \mathrm{MHz}\right): \delta 2.07$ (s, 6H, $\mathrm{CH}_{3}, \mathrm{H}-6,6$ ') 2.57 (s,6H, $\mathrm{CH}_{3}, \mathrm{H}-9,9$ '), 3,83-3,90 (m, 4H, $\mathrm{CH}_{2}, \mathrm{H}-10,10$ '), 5,7 (s, 2H, =CH, H-5,5'), 13,8b (s, 2H, NH); MS(EI): m/z $360[\mathrm{M}]^{+}$. Anal. Calcd for $\mathrm{C}_{18} \mathrm{H}_{20} \mathrm{~N}_{2} \mathrm{O}_{6}: \mathrm{C}$ 60,00, H 5,55, N 7,77. Found: C 60,17, H 5,57, N 7,17\%.

\subsection{2.}

3,3'-\{propane-1,3-diylbis[imino-eth-1-yl-1-ylidene] \}bis(6-methyl-2H-pyran-2,4(3H)-dione) (3b). Pale yellow solid, m.p: 215-217 ${ }^{\circ} \mathrm{C}\left(214-215{ }^{\circ} \mathrm{C}\right)$ [5] (recrystallized from ethanol, TLC-chloroform: methanol, 6:1, $\left.\mathrm{R}_{\mathrm{f}}=0.70\right) ; 3,10 \mathrm{~g}(83 \%)$. IR $\left(\mathrm{KBr}, \mathrm{cm}^{-1}\right): 3471,3068,1701$, 1676, 1573, 1472, 1356, 953, 833, $777{ }^{1} \mathrm{H} \mathrm{NMR}\left(\mathrm{CDCl}_{3}, 300,13 \mathrm{MHz}\right): \delta 2.05-2.21(\mathrm{~m}, 2 \mathrm{H}$, $\left.\mathrm{CH}_{2}, \mathrm{H}-10\right), 2.10$ (s, 6H, $\left.\mathrm{CH}_{3}, \mathrm{H}-7,7^{\prime}\right), 2.64$ (s,6H, $\mathrm{CH}_{3}, \mathrm{H}-9,9$ '), 3.60 (m, 4H, CH $2, \mathrm{H}-10,10$ '), $5.64\left(\mathrm{~s}, 2 \mathrm{H},=\mathrm{CH}, \mathrm{H}-5,5^{\prime}\right), 14.43 \mathrm{~b}(\mathrm{~s}, 2 \mathrm{H}, \mathrm{NH}) ; \mathrm{MS}(\mathrm{EI}): \mathrm{m} / \mathrm{z} 374[\mathrm{M}]^{+}$. Anal. Calcd for $\mathrm{C}_{19} \mathrm{H}_{22} \mathrm{~N}_{2} \mathrm{O}_{6}: \mathrm{C} 60,96, \mathrm{H} 5,88, \mathrm{~N} 7,48$. Found: C 60,69, H 5,88, N 7,35\%.

\subsection{3.}

3,3'-\{propane-1,2-diylbis[imino-eth-1-yl-1-ylidene] \}bis(6-methyl-2H-pyran-2,4(3H)-dione) (3c). Pale yellow solid m.p: $224{ }^{\circ} \mathrm{C}$ (recrystallized from ethanol, TLC-chloroform: methanol, $\left.6: 1, \mathrm{R}_{\mathrm{f}}=0.61\right) ; 2,06 \mathrm{~g}(80 \%) . \mathrm{IR}\left(\mathrm{KBr}, \mathrm{cm}^{-1}\right): 3501,3033,1703,1656,1561,1459,1398,953$, 833, 771. ${ }^{1} \mathrm{H} \mathrm{NMR}\left(\mathrm{CDCl}_{3}, 300,13 \mathrm{MHz}\right): \delta 1.46\left(\mathrm{~d}, 3 \mathrm{H}, \mathrm{CH}_{3}, \mathrm{H}-11\right) 2.05\left(\mathrm{~s}, 6 \mathrm{H}, \mathrm{CH}_{3}\right.$, H-7,7'), 2.59 (s, 3H, CH, H-9), 2.57 (s, 3H, $\mathrm{CH}_{3}, \mathrm{H}-9^{\prime}$ ), 3.65 (t, 2H, $\left.\mathrm{CH}_{2}, \mathrm{H}-10\right), 4,22$ (m, 1H, CH, H-10'), 5.59 (s, 2H, =CH, H-5,5'), 14.62b (s, 2H, NH); MS(EI): m/z $374[\mathrm{M}]^{+}$. Anal. Calcd for $\mathrm{C}_{19} \mathrm{H}_{22} \mathrm{~N}_{2} \mathrm{O}_{6}$ : C 60,96, H 5,88, N 7,48. Found: C 60,69, H 5,95, N 7,39\%. 


\subsection{4.}

3,3'-\{ butane-1,2-diylbis[imino-eth-1-yl-1-ylidene] \}bis(6-methyl-2H-pyran-2,4(3H)-dione)

(3d). Pale yellow solid m.p: $120-121{ }^{\circ} \mathrm{C}$ (recrystallized from ethanol, TLC-chloroform: methanol, 6:1, $\left.\mathrm{R}_{\mathrm{f}}=0.58\right) ; 3,29 \mathrm{~g}(85 \%)$. IR $\left(\mathrm{KBr}, \mathrm{cm}^{-1}\right): 3461,3065,1708,1660,1561,1459$, 1398, 949, 836, 768. ${ }^{1} \mathrm{H}$ NMR $\left(\mathrm{CDCl}_{3}, 300,13 \mathrm{MHz}\right): \delta 1.11\left(\mathrm{t}, 3 \mathrm{H}, \mathrm{CH}_{3}, \mathrm{C}_{2} \mathrm{H}_{5}\right), 1,72(\mathrm{~m}$, 2H, $\mathrm{CH}_{2}, \mathrm{CH}_{2} \mathrm{CH}_{5}$ ), 2.09 (s, 6H, $\mathrm{CH}_{3}, \mathrm{H}-7,7^{\prime}$ ), 2.58 (s, 3H, $\mathrm{CH}_{3}, \mathrm{H}-9$ '), 2,61 (s, 3H, $\mathrm{CH}_{3}$, H-9), 3.67-3.74 (d, 2H, $\left.\mathrm{CH}_{2}, \mathrm{H}-10\right)$, 3.97-4.05 (m, 1H, CH, H-10'), 5.64 (s, 2H, =CH, H-5,5'), 14.64b (s, 2H, NH); MS(EI): m/z $388[\mathrm{M}]^{+}$. Anal. Calcd for $\mathrm{C}_{20} \mathrm{H}_{24} \mathrm{~N}_{2} \mathrm{O}_{6}: \mathrm{C} 61,85, \mathrm{H} \mathrm{6,18,} \mathrm{N}$ 7,21. Found: C 60,02, H 6,22, N 7,05\%.

\subsection{5.}

3,3'-\{2-Methylpropane-1,2-diylbis[imino-eth-1-yl-1-ylidene] \}bis(6-methyl-2H-pyran-2,4(3 H)-dione) (3e). White solid m.p: $206{ }^{\circ} \mathrm{C}$ (recrystallized from ethanol, TLC-chloroform:methanol, 6:1, $\left.\mathrm{R}_{\mathrm{f}}=0.54\right) ; 1,94 \mathrm{~g}(50 \%)$. IR $\left(\mathrm{KBr}, \mathrm{cm}^{-1}\right): 3457,3059,1704$, 1662, 1565, 1464, 1395, 949, 831, 767. ${ }^{1} \mathrm{H}$ NMR $\left(\mathrm{CDCl}_{3}, 300,13 \mathrm{MHz}\right): \delta 1.65\left(\mathrm{~s}, 6 \mathrm{H}, \mathrm{CH}_{3}\right.$, H-11), 2.09 (s, 6H, CH $, \mathrm{H}-7,7^{\prime}$ ), 2.65 (s, 6H, $\mathrm{CH}_{3}, \mathrm{H}-9,9$ '), 3.7 (s, 2H, $\mathrm{CH}_{2}, \mathrm{H}-10$ ), 5.63 (s, $\left.2 \mathrm{H},=\mathrm{CH}, \mathrm{H}-5,5^{\prime}\right), 14.65 \mathrm{~b}(\mathrm{~s}, 2 \mathrm{H}, \mathrm{NH}) ; \mathrm{MS}(\mathrm{EI}): \mathrm{m} / \mathrm{z} 388[\mathrm{M}]^{+}$. Anal. Calcd for $\mathrm{C}_{20} \mathrm{H}_{24} \mathrm{~N}_{2} \mathrm{O}_{6}$ : C 61,85, H 6,18, N 7,21. Found: C 61,30, H 6,28, N 6,99\%.

\section{CONCLUSION}

In conclusion, we have found an efficient and practical procedure for the synthesis in very good yield of 3,3'- $\{$ alkane- $\alpha, \omega$-diylbis[imino-eth-1-yl-1-ylidene] $\}$ bis(6-methyl-2 $H$-pyran-2,4(3H)-dione) derivatives from the condensation of a diamine and dehydroacetic acid in ethanol under ultrasonic irradiation at $30{ }^{\circ} \mathrm{C}$ catalyzed by p-TSA. This method is the simplest, convenient and would be applicable for the synthesis of different types of nitrogen-containing heterocyclic compounds. 


\section{REFERENCES}

[1] (a) Azuma S, Sekizaki S, Akizawa T, Yasuhara T, Nakajima T. Activities of novel polyhydroxylated cardiotonic steroids purified from nuchal glands of the snake, Rhabdophis tigrinus. J. Pharm. Pharmacol, 1986, 38, 388-390.

http://dx.doi.org/10.1111/j.2042-7158.1986.tb04594. (b) Cutler H G, Jacyno J M. Biological activity of (-) harzianopyridone isolated from trichodarma harzianum. Agric. Biol. Chem, 1991, 55, 2629-2631. http://dx.doi.org/10.1111/j.1472-765X.2006

[2] Kashar T I, El-Sehli A H. Synthesis, characterization, antimicrobial and anticancer activity of $\mathrm{Zn}(\mathrm{II}), \mathrm{Pd}(\mathrm{II})$ and $\mathrm{Ru}(\mathrm{III})$ complexes of dehydroacetic acid hydrazone J. Chem. Pharm. Res, 2013, 5, 474-483. http://dx.doi.org/11.1013/JCPR-2013-5-11-474-483

[3] Barman T E, Parck D V, Williams R T. Toxicology and Applied Pharmacology., 1963, 5, 545.

[4] Boutemeur-Kheddis B, Hamdi M, Sellier N, Silva A M S. Study of the reactions of 3-acetoacetyl-7-methyl-2H,5H-pyrano[4,3-b]pyran-2,5-dione with aromatic amines. J. Heterocycl. Chem, 2001, 38, 227-231. http://dx.doi.org/10.1002/jhet.5570380134

[5] Tan S F, Ang K P, Jayachandran H L. Synthesis and characterisation of copper(II), nickel(II) and palladium(II) complexes of some schiff bases of dehydroacetic acid Transition Met. Chem, 1984, 9, 390-395. http://dx.doi.org/10.1007/BF00637026

[6] Wanga H, Zou Y, Zhao X, Shi D. A novel and convenient synthesis of 4-hydroxy-6-methyl-3-(1-(phenylimino) ethyl)-2H-pyran-2-one derivatives under ultrasound irradiation. Ultrasonics Sonochemistry, 2011, 18, 1048-1051. http://dx.doi.org/ 10.1016/j.ultsonch.2011.01.006

[7] Shelke V A, Jadhav S M, Patharkar V R, Shankarwar S G, Munde A S, Chondhekar T K. Synthesis, spectroscopic characterization and thermal studies of some rare earth metal complexes of unsymmetrical tetradentate Schiff base ligand, Arabian journal of chemistry, 2012, 5, 501-507. http://dx.doi.org/10.1016/j.arabjc.2010.09.018

[8] Uz`arevic’K, Rubc`ic M, Stilinovic V, Kaitner B, Cindric M. Keto-enol tautomerism in asymmetric Schiff bases derived from p-phenylenediamine. J. of Molecul. Struct, 2010, 984, 232-239. http://dx.doi.org/10.1016/j.molstruc.2010.09.034 
[9] Djedouani A, Abrigach F, Khoutoul M, Mohamadou A, Bendaas A, A. Oussaid A .Touzani R. Catecholase Activity Investigations using in situ Copper Complexes Continuing Schiff Base Derivatives with a Theoretical Calculation . Orient. J. Chem, 2015, 31(1), 97-105. http://dx.doi.org/10.13005/ojc/310110

[10] Yang G W, Xia X P, Zhao C X. Chin. J. Appl. Chem, 1995, 12, 13.

[11] Ashokkumar M, Mason T, Sonochemistry, Kirk-Othmer : John Wiley and Sons, Encyclopedia of Chemical Technology, 2007.

[12] Suslick K S, Price G J. Interaction of acoustic waves and matter at a molecular or atomic level. Ann. Rev. Mater. Sci, 1999, 29, 295-326.

[13] Cravotto G, Angew C P. Forcing and controlling chemical reactions with ultrasound Chem. Int. Ed, 2007, 46, 5476-5488.

[14] Leighton T. The Acoustic Bubble, Academic Press, London, 1994.

[15] Koda S, Kimurab T, Kondoc T, Mitomed H. A standard method to calibrate sonochemical efficiency of an individual reaction system Ultrason. Sonochem, 2003, 13, 149-156. http://dx.doi.org/10.1016/S1350-4177(03)00084-1

[16] García-Ruano J L, Parra A, Marzo L, Yuste F, Mastranzo V M. One-pot synthesis of sulfonamides from methyl sulfinates using ultrasound.Tetrahedron, 2011, 67, 2905-2910. http://dx.doi.org/ 10/1016/ S0040402011002729.

[17] Shabalala N M, Pagadala R, Jonnalagadda S B. Ultrasonic-accelerated rapid protocol for the improved synthesis of pyrazoles. Ultrason. Sonochem, 2015, 27, 423-429. http://dx.doi.org/10.1016/j.ultsonch.2015.06.005

[18] Wakeford C A, R Blackburn R, Lickiss P D, Effect of ionic strength on the acoustic generation of nitrite, nitrate and hydrogen peroxide. Ultrason. Sonochem, 1996, 3, 141-148. http://dx.doi.org/10.1016/S1350-4177(98)00039-X

[19] Ji S J, Shen Z L, Gu D G, Huang X Y. Ultrasound-promoted alkynylation of ethynylbenzene to ketones under solvent-free condition Ultrason. Sonochem, 2005, 12, 161-163. http://dx.doi.org/10.1016/j.ultsonch.2004.01.036

[20] Li J T, Sun M X, Yin Y. Ultrasound promoted efficient method for the cleavage of 3-aryl-2,3-epoxyl-1-phenyl-1-propanone with indole Ultrason. Sonochem, 2010, 17, 359-362. 
http://dx.doi.org/10.1016/j.ultsonch.2009.09.004

[21] (a) Ni C L, Song X H, Yan H, Song X Q, Zhong R G. Improved synthesis of diethyl 2,6-dimethyl-4-aryl-4H-pyran-3,5-dicarboxylate under ultrasound irradiation. Ultrason. Sonochem, 2010, 17, 367-379 http://dx.doi.org/10.1016/j.ultsonch.2009.09.006; (b) Zou Y, Wu H, Hu Y, Liu H, Zhao X, Ji H L, Shi D Q. A novel and environment-friendly method for preparing dihydropyrano[2,3-c]pyrazoles in water under ultrasound irradiation. Ultrason. Sonochem, 2011, 18, 708-712. http://dx.doi.org/10.1016/j.ultsonch.2010.11.012 [22] Venkatachalam G, Ramesh R. Ruthenium (II) Schiff base complexes of [ONNO]-type mediated transfer hydrogenation of ketones. Inorg chem. commun, 2005, 8, 1009-1013. http://dx.doi.org/10.1016/j.inoche.2005.08.004

\section{How to cite this article:}

Benosmane N, Boutemeur B, Hamdi SM, Hamdi M. A convenient synthesis of pyrandione derivatives using p-toluenesulfonic acid as catalyst under ultrasound irradiation. J. Fundam. Appl. Sci., 2016, 8(3), 826-838. 